S. C. B. Raper · J. M. Gregory · T. J. Osborn

\title{
Use of an upwelling-diffusion energy balance climate model to simulate and diagnose AVOCM results
}

Received: 27 April 1999 / Accepted: 13 September 2000

\begin{abstract}
We demonstrate that a hemispherically averaged upwelling-diffusion energy-balance climate model (UD/EBM) can emulate the surface air temperature change and sea-level rise due to thermal expansion, predicted by the HadCM2 coupled atmosphere-ocean general circulation model, for various scenarios of anthropogenic radiative forcing over 1860-2100. A climate sensitivity of $2.6^{\circ} \mathrm{C}$ is assumed, and a representation of the effect of sea-ice retreat on surface air temperature is required. In an extended experiment, with $\mathrm{CO}_{2}$ concentration held constant at twice the control run value, the HadCM2 effective climate sensitivity is found to increase from about $2.0{ }^{\circ} \mathrm{C}$ at the beginning of the integration to $3.85{ }^{\circ} \mathrm{C}$ after 900 years. The sea-level rise by this time is almost $1.0 \mathrm{~m}$ and the rate of rise fairly steady, implying that the final equilibrium value (the 'commitment') is large. The base UD/EBM can fit the 900-year simulation of surface temperature change and thermal expansion provided that the time-dependent climate sensitivity is specified, but the vertical profile of warming in the ocean is not well reproduced. The main discrepancy is the relatively large mid-depth warming in the HadCM2 ocean, that can be emulated by (1) diagnosing depthdependent diffusivities that increase through time; (2) diagnosing depth-dependent diffusivities for a pure-diffusion (zero upwelling) model; or (3) diagnosing higher depth-dependent diffusivities that are applied to temperature perturbations only. The latter two models can be run to equilibrium, and with a climate sensitivity of $3.85{ }^{\circ} \mathrm{C}$, they give sea-level rise commitments of $1.7 \mathrm{~m}$ and $1.3 \mathrm{~m}$, respectively.
\end{abstract}

S. C. B. Raper $(\bowtie) \cdot$ T. J. Osborn

Climatic Research Unit,

University of East Anglia,

Norwich, NR4 7TJ, UK

J. M. Gregory

Hadley Centre for Climate Prediction and Research,

The Met Office,

Bracknell, RG12 2SY, UK

\section{Introduction}

Simple 1-D box-diffusion energy-balance climate models have been used in many studies of both temperature and sea-level change (e.g. Hoffert et al. 1980; Gornitz et al. 1982; Harvey and Schneider 1985; Hoffert and Flannery 1985). The Intergovernmental Panel on Climate Change (IPCC) Scientific Assessments have used simple climate models to make projections of global-mean temperature and thermal expansion for a wide range of emission scenarios and climate sensitivities (Bretherton et al. 1990; Kattenberg et al. 1996; Warrick et al. 1996). In the IPCC Second Assessment Report (SAR), justification for this approach was based on comparisons with atmosphere-ocean general circulation model (A/OGCM) results (Kattenberg et al. 1996). In the main, these featured a comparison with the GFDL model results of R. Stouffer (personal communication) and Manabe and Stouffer (1994). However, it was also reported (Raper and Cubasch 1996) that the agreement between the simple model and the MPI A/OGCM (Cubasch et al. 1992) was less good. Through comparisons with another A/OGCM, this work commences with the identification of the cause of the latter disagreement and a modification of the simple model. The basic model used here is the upwelling-diffusion energy-balance model (UD/ EBM) of Wigley and Raper (1987, 1992) modified by Raper et al. (1996). This model is developed further in the present study and alternatives are explored.

The A/OGCM results used are those of the Hadley Centre model (HadCM2: Mitchell et al. 1995; Johns et al. 1997; Mitchell and Johns 1997). Five HadCM2 experiments are studied starting at nominal model year 1860: (1) a control with constant $\mathrm{CO}_{2}$ concentrations; (2) an experiment in which the $\mathrm{CO}_{2}$ concentration was increased gradually, to represent historic and possible future changes in forcing, due to all greenhouse gases (based on IPCC scenario IS92a) and denoted GHG; (3) an experiment (SUL) in which the direct radiative effects of sulfate aerosols are represented together with the $\mathrm{CO}_{2}$ 
increase from (2); (4) a scenario in which future $\mathrm{CO}_{2}$ concentrations increase less rapidly, based on IS92d and denoted $\mathrm{D}$; and (5) an experiment in which the $\mathrm{CO}_{2}$ concentration is increased at a rate of $1 \%$ per year until it reaches double its initial value in year 1930 and is then held constant thereafter ( 900 years of this $2 \times \mathrm{CO}_{2}$ stabilisation scenario are considered). The global mean radiative forcing for the experiments (2) to (5) are shown in Fig. 1.

The spatial patterns of the GHG and SUL forcing are described by Mitchell et al. (1995); for the UD/EBM the greenhouse gas forcing is assumed to be uniform and the sulfate aerosol forcing is specified in four boxes representing the land and ocean in each hemisphere, on the basis of the forcing used in HadCM2. The HadCM2 perturbation experiment results, for comparison with the simple climate model results, are represented as differences from the corresponding year in the control run (definition 2 of Cubasch et al. 1994).

The two factors that dictate a climate model's response to transient forcing changes are the climate sensitivity and the ocean heat uptake. These two factors also dictate the equilibrium temperature change and thermal expansion commitment. In the simple climate models used here the climate sensitivity is prescribed and usually assumed to be constant. We explore the validity of this assumption by calculating the HadCM2 effective climate sensitivity (following Murphy 1995). The role of the simple climate model is to simulate the second factor, ocean heat uptake, by a simplified representation of the physical processes. As well as seeking to develop a model which fits the HadCM2 results for diverse scenarios and time scales, the aim of the study is to assess the $2 \times \mathrm{CO}_{2}$ global warming and thermal expansion commitment in the HadCM2 model. For the latter we explore the heat penetration in the HadCM2 model within the framework of a simple climate model.

\section{Reproducing HadCM2 results 1860 to 2100}

This section describes the tuning of the upwelling-diffusion energy balance climate model $(\mathrm{UD} / \mathrm{EBM})$ to reproduce the HadCM2

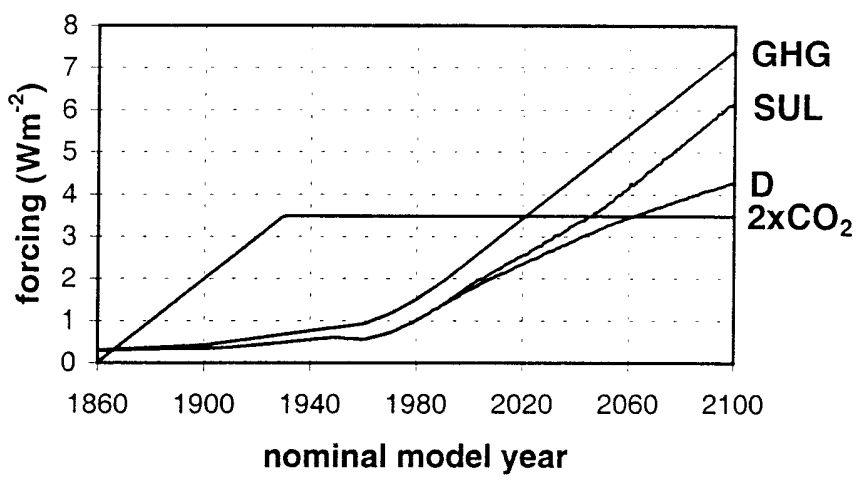

Fig. 1 Global mean radiative forcing for the GHG, SUL, D and $2 \times \mathrm{CO}_{2}$ experiments results, for three forcing scenarios over 1860 to 2100 . An initial comparison is made using the simple climate model updated by Raper et al. (1996). The model comprises a simple energy balance model coupled to a one-dimensional ocean in which the vertical mixing processes in the ocean are represented by vertical diffusivity and upwelling. The thermohaline circulation intensity is represented by the upwelling rate in the main water column with implicit high latitude sinking in the polar regions. For the change in radiative forcing due to a doubling of carbon dioxide concentration, $\Delta Q_{2 \mathrm{x}}$, a value of $3.47 \mathrm{Wm}^{-2}$ is used throughout this study. This value was derived from a HadCM2 simulation and is less than the value of $4.37 \mathrm{Wm}^{-2}$ used for the IPCC SAR (Kattenberg et al. 1996), in part because it allows for stratospheric adjustment. The most important UD/EBM model parameter is the climate sensitivity, $\Delta T_{2 \mathrm{x}}$, which is defined as the equilibrium global-mean temperature change for a doubling in $\mathrm{CO}_{2}$ concentration. For simulating HadCM2 results to 2100, an appropriate value of $\Delta T_{2 \mathrm{x}}$ is about $2.6{ }^{\circ} \mathrm{C}$ (but see Sect. 5).

The UD/EBM model differentiates the hemispheres, and the land and ocean regions in each hemisphere. A parameter, $R$, specifies the ratio of the equilibrium temperature changes over land versus ocean. $R$, together with land/ocean $(k l o)$ and inter-hemispheric (kns) exchange coefficients determine the evolving land/ ocean and inter-hemispheric temperature change contrasts. Other parameters affecting the model's response are the mixed-layer depth $(h)$, the oceanic vertical diffusivity $(K)$, the initial upwelling rate $\left(w_{0}\right)$, and the temperature change of the incoming bottom water relative to the mixed layer change $(\Pi)$. To minimise the number of parameters, both the vertical diffusivity and the upwelling rate are assumed to be vertically uniform (although, in Sect. 6 a depth-dependent diffusivity model is explored).

Most transient A/OGCM simulations show a reduction in deep water formation rate as greenhouse-gas-induced warming increases. This weakening of the thermohaline circulation occurs because of changes in surface water and heat fluxes at high latitudes. In the UD/EBM, this can be represented by a variable upwelling rate $(w)$, using a simple relationship between $w$ and the mixed layer temperature change $\left(\Delta T_{M}\right)$ given by

$w(t)=w_{0}\left(1-\Delta T_{M} / \Delta T_{M}^{+}\right)$

where $w(t) \geq 0.0 \mathrm{~m} \mathrm{a}^{-1} . \Delta T_{M}^{+}$is the tuneable parameter representing the magnitude of warming that would result in zero upwelling.

For the initial comparison, excepting $\Delta Q_{2 \mathrm{x}}$, parameter values are the same as those used in the IPCC SAR; $R=1.3$, $k l o=1.0 \mathrm{Wm}^{-2}{ }^{\circ} \mathrm{C}^{-1}, \quad k n s=1.0 \mathrm{Wm}^{-2}{ }^{\circ} \mathrm{C}^{-1}, \quad h=90 \mathrm{~m}$, $K=1 \mathrm{~cm}^{2} \mathrm{~s}^{-1}, w_{0}=4 \mathrm{~m} \mathrm{a}^{-1}, \Delta T_{M}^{+}=7^{\circ} \mathrm{C}, \Pi=0.2$. Results of the initial comparison are shown in Fig. 2 for forcing scenarios GHG, SUL and D. Evidently the simple climate model with IPCC SAR parameters, denoted 'UD SAR' (1 in Table 1), underestimates the temperature change and overestimates the thermal expansion compared to the HadCM2 results. Two possible reasons for this difference have been identified and can be corrected.

First, the influence of changing sea-ice cover has not been modelled. In the SAR formulation of the UD/EBM, the surface air temperature change over the ocean is assumed to be the same as the ocean mixed layer temperature change; if sea-ice cover is reduced, however, the air temperature will exhibit additional warming as the cold ice temperature felt by the atmosphere is replaced by the warmer water surface temperature. In the comparison with the ECHAM1/LSG model, Raper and Cubasch (1996) noted that the A/OGCM air temperature warmed more than the mixed layer temperature by a factor of 1.2 (a factor virtually constant through the simulations). In the present study, the UD/EBM is extended to include a simple representation of this sea-ice effect by introducing a sea-ice parameter, CICE, by which we multiply the mixed layer change to yield the surface air temperature change. Diagnosis of the HadCM2 perturbation experiments shows that the same value $(\mathrm{CICE}=1.2)$ is suitable.

A second reason for the different results in the initial comparison may be that the changes in the upwelling rate predicted by Eq. (1) with $\Delta T_{M}^{+}=7^{\circ} \mathrm{C}$ are not appropriate. A transient reduction in the rate of upwelling of cold water allows the surface warming to 

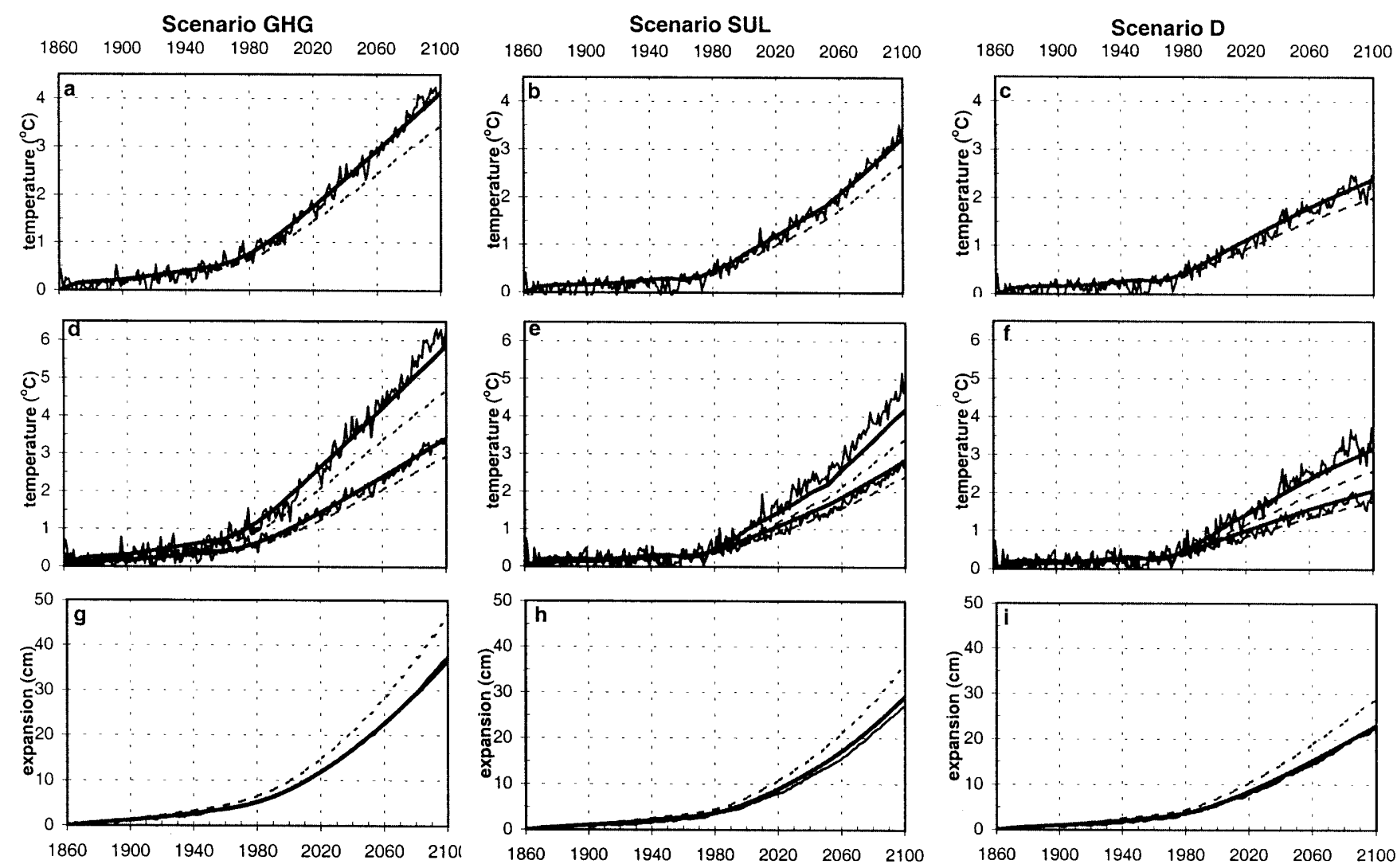

Fig. 2a-i Comparison of HadCM2 results for forcing scenarios GHG, SUL and D with simulations by a UD/EBM. a-c Global and $\mathbf{d}-\mathbf{f}$ land and ocean mean temperature changes are shown together

with $\mathbf{g}-\mathbf{i}$ thermal expansion: HadCM2 thin solid line; UD SAR dashed; UD tuned thick solid. In $\mathbf{d}-\mathbf{f}$ the land temperature changes are larger than the ocean changes

Table 1 Summary of UD/EBMs discussed in the text, in order of appearance. The first four model settings fit the HadCM2 data for various scenarios to 2100. Model settings 5 and 6 give good results for the full 900 years of the $2 \times \mathrm{CO}_{2}$ experiment

\begin{tabular}{|c|c|c|c|}
\hline UD model description & Diffusivity treatment & Upwelling rate & Other parameter values \\
\hline \multicolumn{4}{|l|}{ Uniform area } \\
\hline 1 UD SAR (Raper et al. 1996) & Uniform $1.0 \mathrm{~cm}^{2} \mathrm{~s}^{-1}$ & $\begin{array}{l}\text { Governed by } \Delta T_{M} \\
\quad \text { with } \Delta T_{M}{ }^{+}=7{ }^{\circ} \mathrm{C}\end{array}$ & As given in Table 2 (top) \\
\hline $\begin{array}{l}2 \text { UD tuned, includes sea-ice } \\
\text { parameter, CICE }\end{array}$ & Uniform $1.0 \mathrm{~cm}^{2} \mathrm{~s}^{-1}$ & $\begin{array}{l}\text { Governed by } \Delta T_{M} \text { with } \\
\Delta T_{M}{ }^{+}=12{ }^{\circ} \mathrm{C} \text { or diagnosed }\end{array}$ & As given in Table 2 (bottom) \\
\hline $3 \mathrm{UD} \mathrm{k}=2$ & Uniform $2.0 \mathrm{~cm}^{2} \mathrm{~s}^{-1}$ & $4 \mathrm{~m} \mathrm{a}^{-1}$ & As given in Table 2 (bottom) ${ }^{\mathrm{a}}$ \\
\hline \multicolumn{4}{|l|}{ Depth-dependent area } \\
\hline 5 Pure diffusion & $\begin{array}{l}\text { Diagnosed mean values } \\
\text { for first } 100 \text { years }\end{array}$ & Zero & $\begin{array}{l}\text { As given in Table } 2 \text { (bottom); except } \\
\text { diagnosed climate sensitivity }\end{array}$ \\
\hline $6^{\prime} 2 K^{\prime} \mathrm{UD} / \mathrm{EBM}$ & $\begin{array}{l}\text { Two sets of diagnosed } \\
\text { K profiles }\end{array}$ & $4 \mathrm{~m} \mathrm{a}^{-1}$ & Same as model 5 \\
\hline
\end{tabular}

\footnotetext{
${ }^{\text {a }}$ Used with both $\Delta T_{2 \mathrm{x}}=2.6^{\circ} \mathrm{C}$ and with diagnosed climate sensivitity
}

penetrate deeper into the ocean and hence slows the global mean surface warming and increases the thermal expansion (Wigley and Raper 1987; Harvey 1994). In A/OGCMs such as HadCM2, the circulation appears in the form of large-scale meridional overturning cells, as shown by the meridional overturning stream function (Fig. 3). It is not obvious how to relate the advective cells, with their detailed spatial variation, to the single upwelling velocity of the one-dimensional model. For simplicity, we take the maximum value of the North Atlantic overturning stream function (using decadal means), denoted by $S$, as a measurement of the strength of the thermohaline circulation in HadCM2. If changes in this quantity are used to scale the upwelling in both hemispheres according to

$w(t)=w_{0} S(t) / S_{0}$

where $S_{0}$ is the initial value, $w$ declines as shown in Fig. 4 for the GHG, SUL and D scenario results. The decline is smaller than that predicted by Eq. (1) for the SAR parameters (i.e. $\Delta T_{M}^{+}=7^{\circ} \mathrm{C}$, shown in Fig. 4 for the GHG case), and may contribute to the too large expansion in the 'UD SAR' simulations. An appropriate 
Fig. 3 Meridional overturning stream function for nominal years $1860-1990$ of the HadCM2 control experiment. Flow follows isolines, with higher values to the left
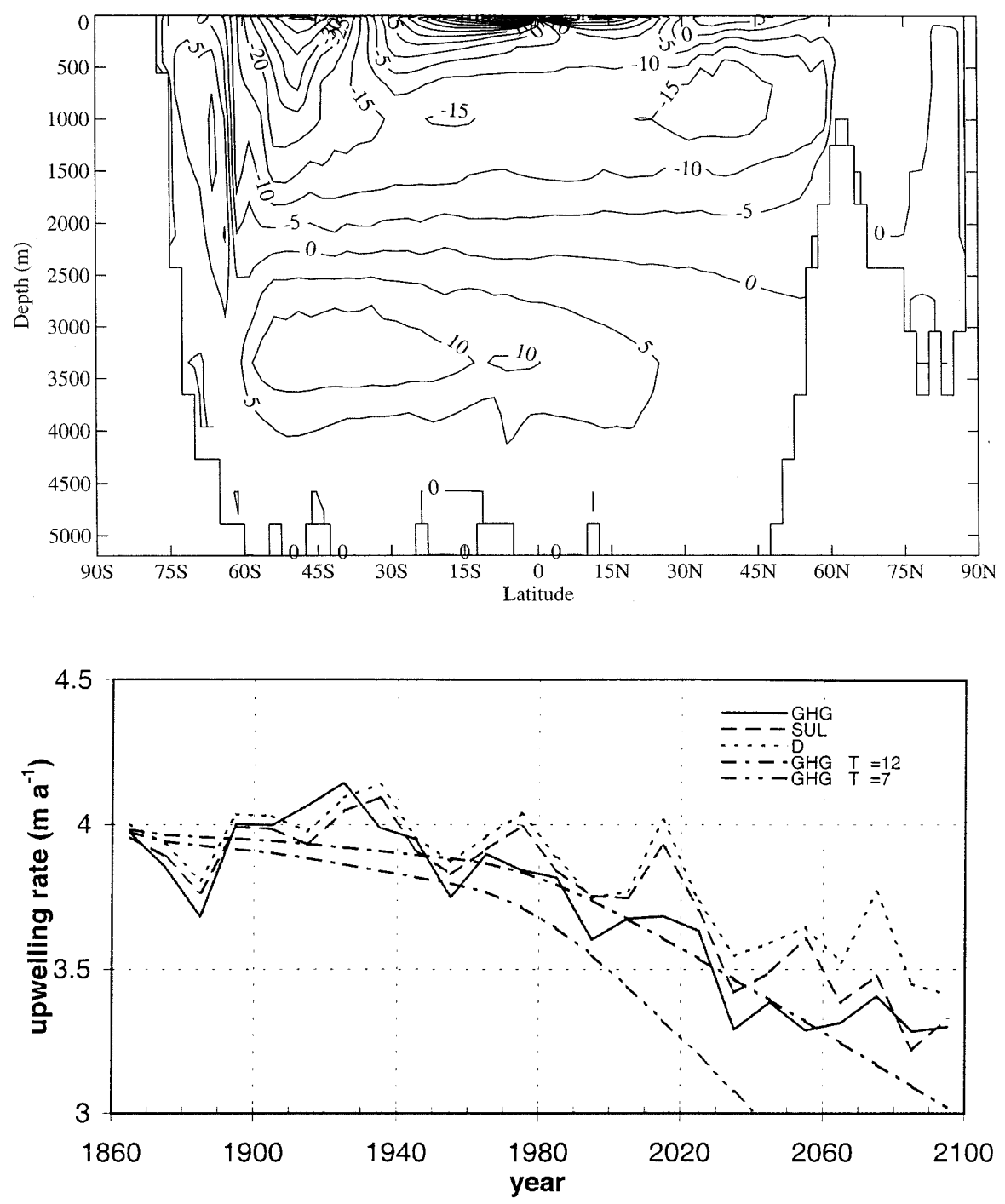

Fig. 4 Upwelling rate for HadCM2 GHG, SUL and D scenarios based on the maximum value of the decadal mean North Atlantic stream function. Also shown, for the GHG case, are the scaled upwelling rates for the UD/EBM when $\Delta T_{M}^{+}=7^{\circ} \mathrm{C}$ and $12^{\circ} \mathrm{C}$ value of $\Delta T_{M}^{+}$to fit the diagnosed decline of the thermohaline circulation for all three scenarios shown in Fig. 3 is $12{ }^{\circ} \mathrm{C}$; this gives a good fit to the diagnosed $w$ values until 2060 for the GHG case (Fig. 4) and even better fits to the SUL and D $w$ values (not shown).

Another potential cause for differences in the thermal expansion results is that, for the UD model, thermal expansion is calculated from hemispheric-mean temperature profiles, whereas for HadCM2, thermal expansion is calculated at each grid-point (following Gregory 1993) and subsequently averaged. These different procedures give different results, because the equation of state is non-linear, but in practice the discrepancy is less than $2 \%$ for HadCM2.

A second set of simulations is performed with the UD/EBM using the parameter values summarised in Table 2 and denoted 'UD tuned' ( 2 in Table 1 ). Additional to using $\Delta T_{M}^{+}=12^{\circ} \mathrm{C}$ and incorporating the sea-ice effect, $h$ is set to the effective annual and global-mean mixed layer depth simulated by HadCM2. The value for the parameter $R$ is taken as the ratio of the land versus ocean temperature change for the last 100 years of the 900 year $2 \times \mathrm{CO}_{2}$ simulation. Values of klo and kns were tuned to give good simulations of the land/ocean and north/south temperature change contrasts. Figure 2 shows that the 'UD tuned' results give a good fit to the HadCM2 results for all three scenarios. It is, perhaps, fortuitous that the value of $1.0 \mathrm{~cm}^{2} \mathrm{~s}^{-1}$ for the diffusivity gives just the right amount of heat flux into the ocean without any need for tuning.
Table 2 UD/EBM parameter settings used for the results shown in Fig. 2 . In both cases $\Delta T_{2 \mathrm{x}}=2.6^{\circ} \mathrm{C}, K=1 \mathrm{~cm} \mathrm{~s}^{-1}$ and $\Pi=0.2$

\begin{tabular}{llllllc}
\hline $\begin{array}{l}\text { Parameter } \\
\text { units }\end{array}$ & $\begin{array}{l}h \\
\mathrm{~m}\end{array}$ & $\mathrm{CICE}$ & $R$ & $\begin{array}{l}\mathrm{klo} \\
\mathrm{Wm}^{-2}{ }^{\circ} \mathrm{C}^{-1}\end{array}$ & $\begin{array}{l}\mathrm{kns} \\
\mathrm{Wm}^{-2}{ }^{\circ} \mathrm{C}^{-1}\end{array}$ & $\begin{array}{l}\Delta T_{M}^{+} \\
{ }^{\circ} \mathrm{C}\end{array}$ \\
\hline UD SAR & 90 & 1.0 & 1.3 & 1.0 & 1.0 & 7 \\
UD tuned & 60 & 1.2 & 1.4 & 0.5 & 0.5 & 12 \\
\hline
\end{tabular}

The mechanism by which the upwelling diffusion model predicts an increase in expansion when $w$ declines is dependent on the assumption that the process by which heat penetrates the ocean below the mixed layer can be represented by a diffusive term. Church et al. (1991) argue that the main process for heat penetration is subduction along isopycnals. In view of this uncertainty, it is useful to investigate alternative ways of fitting the UD/EBM to the HadCM2 results without varying the upwelling rate through time.

Using the 'UD tuned' parameter values but a constant upwelling rate of $w=4 \mathrm{~m} \mathrm{a}^{-1}$, the temperature change is overestimated and the thermal expansion underestimated. There are alternative ways to increase the oceanic heat uptake and fit the HadCM2 results. A reasonable fit for both surface temperature change and thermal expansion is obtained when the diffusivitiy, $K$, is increased to $2 \mathrm{~cm}^{2} \mathrm{~s}^{-1}$ (model 3 in Table 1). Another parameter that can 
be adjusted is $\Pi$, which governs the temperature change of the incoming bottom water (Bretherton et al. 1990; Wigley and Raper 1993; Harvey 1994). A value of $\Pi=0.85$ (model 4 in Table 1) gives a good fit to the HadCM2 surface temperature change and thermal expansion. Use of such large values of $\Pi$ can lead, however, to unrealistic instability in the global mean ocean column. If instability occurs, the warming is redistributed by a simple convection algorithm to achieve a statically stable temperature profile.

The three alternative UD/EBM simulations (models 2, 3 and 4 in Table 1) that give a good fit to the HadCM2 GHG experiment results, for surface temperature change and thermal expansion, are compared in terms of their vertical profiles of global mean ocean temperature change for the final decade (2091-2100, Fig. 5). Note that, for all three simulations, the UD/EBM underestimates the mid-depth 1000 to $2500 \mathrm{~m}$ warming simulated by HadCM2. This phenomenon is investigated further in following sections.

\section{Initial temperature profiles}

The observed (Levitus 1982), initial HadCM2 and UD/ EBM annual-mean ocean-mean temperature profiles are compared in Fig. 6. Since the thermal expansion coefficient is a function of the temperature, differences between the inital temperature profiles can lead to differences in the calculated thermal expansion. The initial HadCM2 temperature profile is taken as the first decadal mean of the control run following the spin-up period. The initial UD model temperature profile below the mixed layer is given by a declining exponential (the steady-state solution for the UD model):

$\theta(z)=\alpha+\beta \mathrm{e}^{-z w / K}$

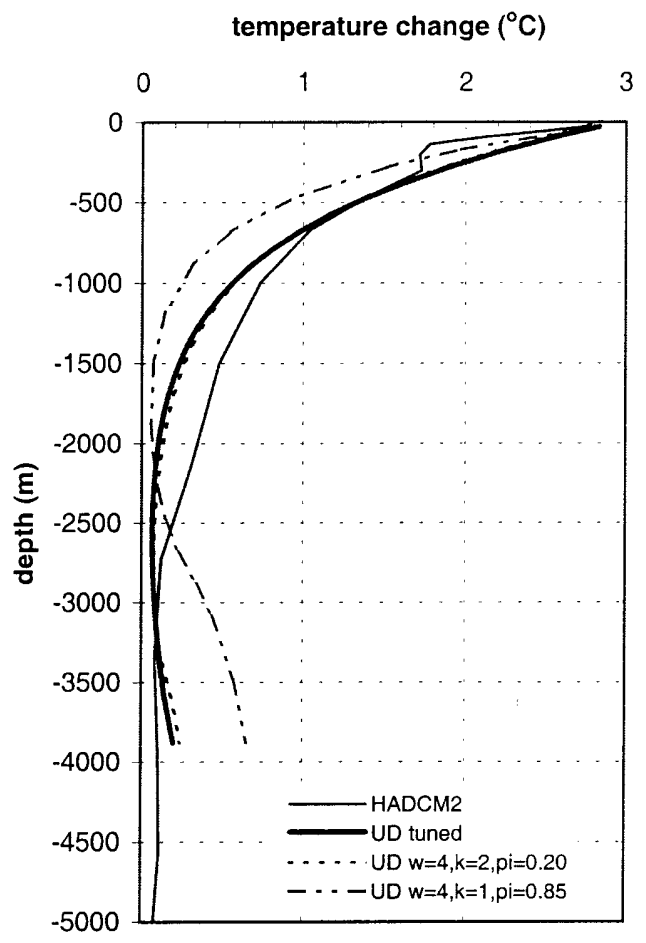

Fig. 5 Ocean mean temperature change profiles by decade 2091-2100 for the GHG forcing scenario. The results for three alternative UD/ EBM parameter settings are shown together with the HadCM2 results. All the profiles correspond to a similar thermal expansion

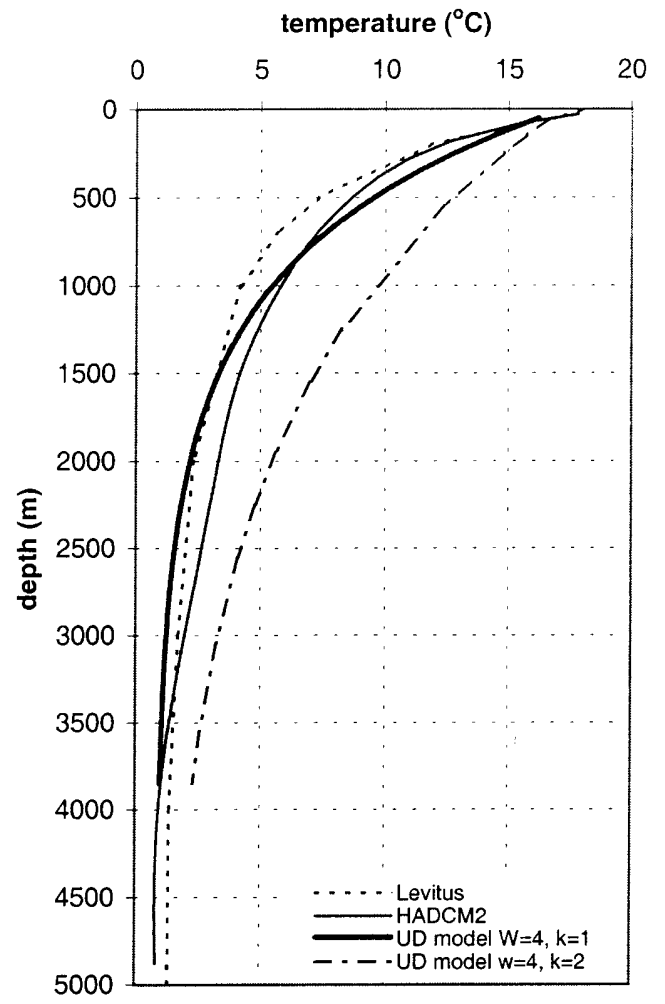

Fig. 6 Observed global mean ocean temperature profile from Levitus (1982) compared with the first decade mean profile from the HadCM2 control run and the initial profiles from the UD model with $w=4 \mathrm{~m} \mathrm{y}^{-1}$ and $K=1 \mathrm{~cm}^{2} \mathrm{~s}^{-1}$ or $2 \mathrm{~cm}^{2} \mathrm{~s}^{-1}$

where $z$ is depth below the mixed layer, and $\alpha$ and $\beta$ are constants that can be calculated when the temperature at two levels is specified (here the mixed layer at $17.2{ }^{\circ} \mathrm{C}$ and bottom layer at $1{ }^{\circ} \mathrm{C}$ ).

The UD model initial temperature profile for $K=1 \mathrm{~cm}^{2} \mathrm{~s}^{-1}$ and $w=4 \mathrm{~m} \mathrm{y}^{-1}$ (used in models 1,2 and 4) shows reasonable agreement with the Levitus data and initial HadCM2 profiles and in this respect is superior to the UD model profile for $K=2 \mathrm{~cm}^{2} \mathrm{~s}^{-1}$ (used in model 3). The HadCM2 profile is warmer than the observations throughout the mid ocean (Fig. 6), due to a warming that occurred during the 510-year spin up (Johns et al. 1997). This warming continues throughout the 900 year control run (amounting to a further $0.2{ }^{\circ} \mathrm{C}$ ). It may be that the distinctive mid-ocean warming towards the end of the GHG forcing scenario is associated with the same processes that also produce this warming tendency in the control run.

\section{Time dependence of the climate sensitivity}

The HadCM2 $2 \times \mathrm{CO}_{2}$ stabilisation run gives an important opportunity for comparison with UD/EBM results. The importance stems from policy makers' need for a longer term perspective on the effects of greenhouse gas stabilisation at various levels (Schimel et al. 1997). 
The forcing for the HadCM2 $2 \times \mathrm{CO}_{2}$ stabilisation run extends for 900 years out to nominal year 2760; the first 140 years are plotted in Fig. 1. Although a value of $2.6{ }^{\circ} \mathrm{C}$ for the climate sensitivity of HadCM2 appeared to be appropriate for the model comparison of Sect. 2, the HadCM2 global mean warming results for the $2 \times \mathrm{CO}_{2}$ experiment show increases above $3.0^{\circ} \mathrm{C}$ and the temperature is still rising almost linearly after 900 years (Fig. 7).

In the UD/EBM it is assumed that the strengths of the feedbacks on global mean surface air temperature change are constant and are encapsulated in the feedback parameter $(\lambda)$ which can be deduced directly from
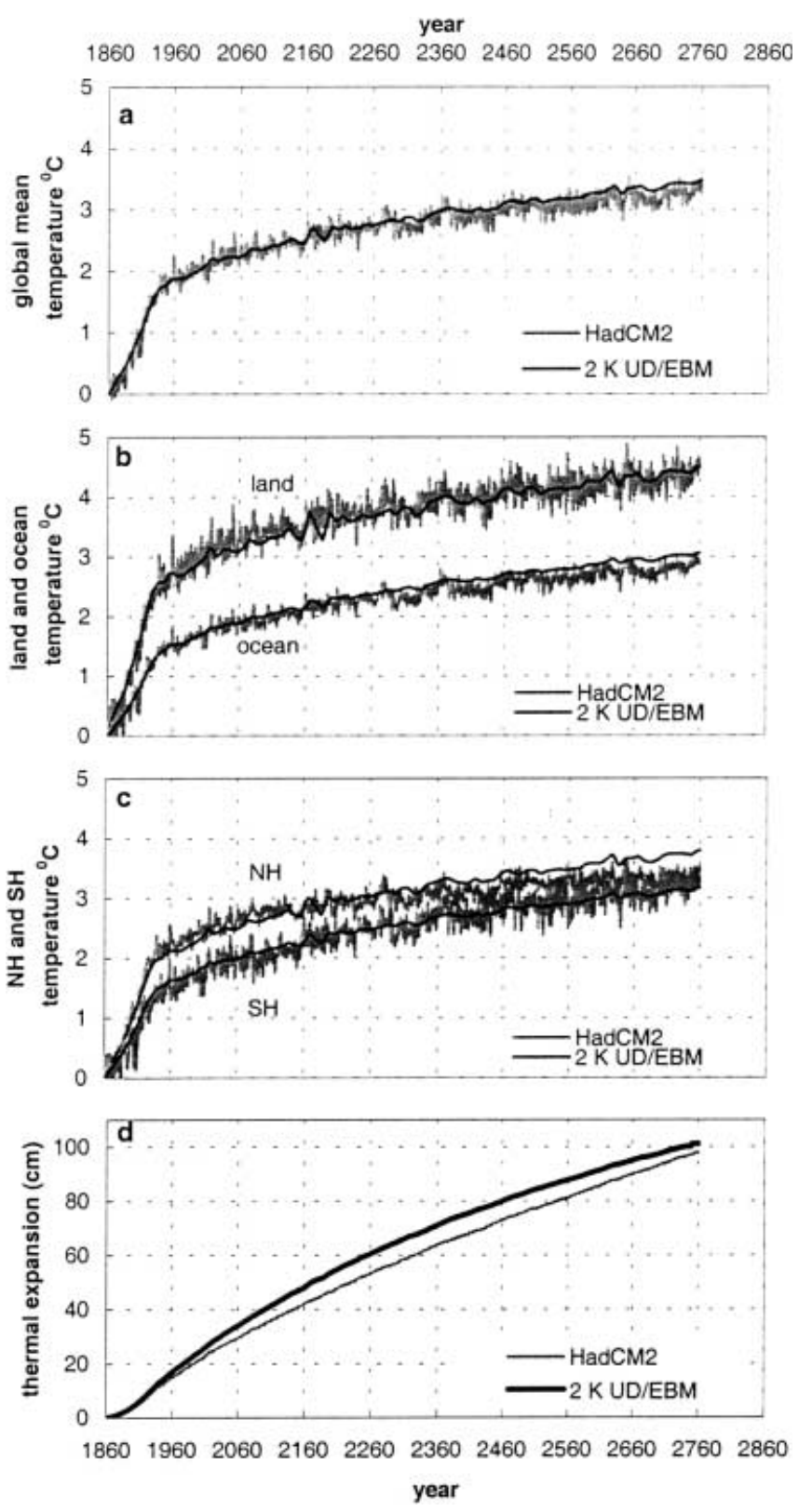

Fig. 7a-d $\mathrm{HadCM} 22 \mathrm{xCO}_{2}$ results compared to depth-dependent ' $2 \mathrm{~K}$ ' $\mathrm{UD} / \mathrm{EBM}$ results. Input to the $\mathrm{UD} / \mathrm{EBM}$ includes time varying effective climate sensitivity and constant upwelling rate, $w=4 \mathrm{~m} \mathrm{y}^{-1}$ the $\mathrm{CO}_{2}$-doubling climate sensitivity. However, Murphy (1995) found that the feedbacks in the UKTR model were not constant but rather increased in time. He defined an 'effective' climate sensitivity as the equilibrium response to a doubling of $\mathrm{CO}_{2}$ which would occur if the A/OGCM was run to equilibrium with feedback strengths, realised at a particular time, held fixed.

The A/OGCM effective climate sensitivity can be calculated from the HadCM2 results within the framework of the EBM used here. Assuming the heat capacity of the land is zero, the effective feedback parameter, $\lambda(t)$, can be estimated from

$f_{O} C d \Delta T_{M} / d t=\Delta Q-\lambda \Delta T_{G}-f_{O} \Delta F$

where $f_{O} C d \Delta T_{M} / d t$ is the rate of change in heat content of the mixed layer, $\Delta T_{G}$ is the global mean surface temperature change and $f_{O} \Delta F$ is the heat flux into the deeper ocean, $f_{O}$ being the ocean area (as a fraction of the Earth's) and $C$ the heat capacity of the mixed layer (see also Gregory and Mitchell 1997).

The resulting estimate of the HadCM2 effective climate sensitivity (i.e. $\left.\Delta Q_{2 x} / \lambda(t)\right)$ for each decadal average of the $2 \times \mathrm{CO}_{2}$ integration is shown in Fig. 8a. The effective climate sensitivity rises first steeply and then more slowly, from a value of about $2{ }^{\circ} \mathrm{C}$ at the beginning of the integration to $3.85^{\circ} \mathrm{C}$ after 900 years. The changes in the effective climate sensitivity resemble those of the global mean temperature. Indeed, Fig. 8b shows that, apart from the initial decades, there is a quasilinear relationship between the two series. There is some evidence of an increase in the slope of the relationship for temperature changes $>2{ }^{\circ} \mathrm{C}$ that may be related to the change in the forcing (Fig. 1). The nature of the increasing positive feedback in the $2 \times \mathrm{CO}_{2}$ experiment has been investigated by Senior and Mitchell (2000) who find that the time dependence is associated with differences in cloud feedback arising from inter-hemispheric temperature differences due to the slower warming rate of the Southern Ocean.

The effective climate sensitivities for the GHG, SUL and $\mathrm{D}$ scenarios are shown in Fig. $8 \mathrm{c}-\mathrm{h}$, with corresponding plots showing their relationship to surface temperature change. These simulations also exhibit a climate sensitivity that depends upon climate state, but the increase in effective climate sensitivity per degree surface temperature change is smaller than that for the $2 \times \mathrm{CO}_{2}$ experiment. The results show that a value of $2.6^{\circ} \mathrm{C}$ is a reasonable mean value for the climate sensitivity over 1860-2100, explaining the good results obtained using this value in Sect. 2.

\section{Time- and depth-dependent effective diffusivities in the long $2 \times \mathrm{CO}_{2}$ stabilisation run}

UD/EBM simulations were carried out using the 900 year $2 \times \mathrm{CO}_{2}$ forcing and the three alternative parameter settings found to give a good fit to HadCM2 results for 1860 to 2100 (models 2, 3 and 4 in Table 1). For the 'UD 
Fig. 8a-h Effective climate sensitivity for the HadCM2 $2 \times \mathrm{CO}_{2}$, GHG, SUL and Scenario $\mathrm{D}$ experiments plotted against time (a, $\mathbf{c}$, e and $\mathbf{g})$ and global mean surface temperature change (b, $\mathbf{d}, \mathbf{f}$ and $\mathbf{h})$. Also marked on $\mathbf{b}$ with a circle is the climate sensitivity of the mixed layer ocean version of HadCM2
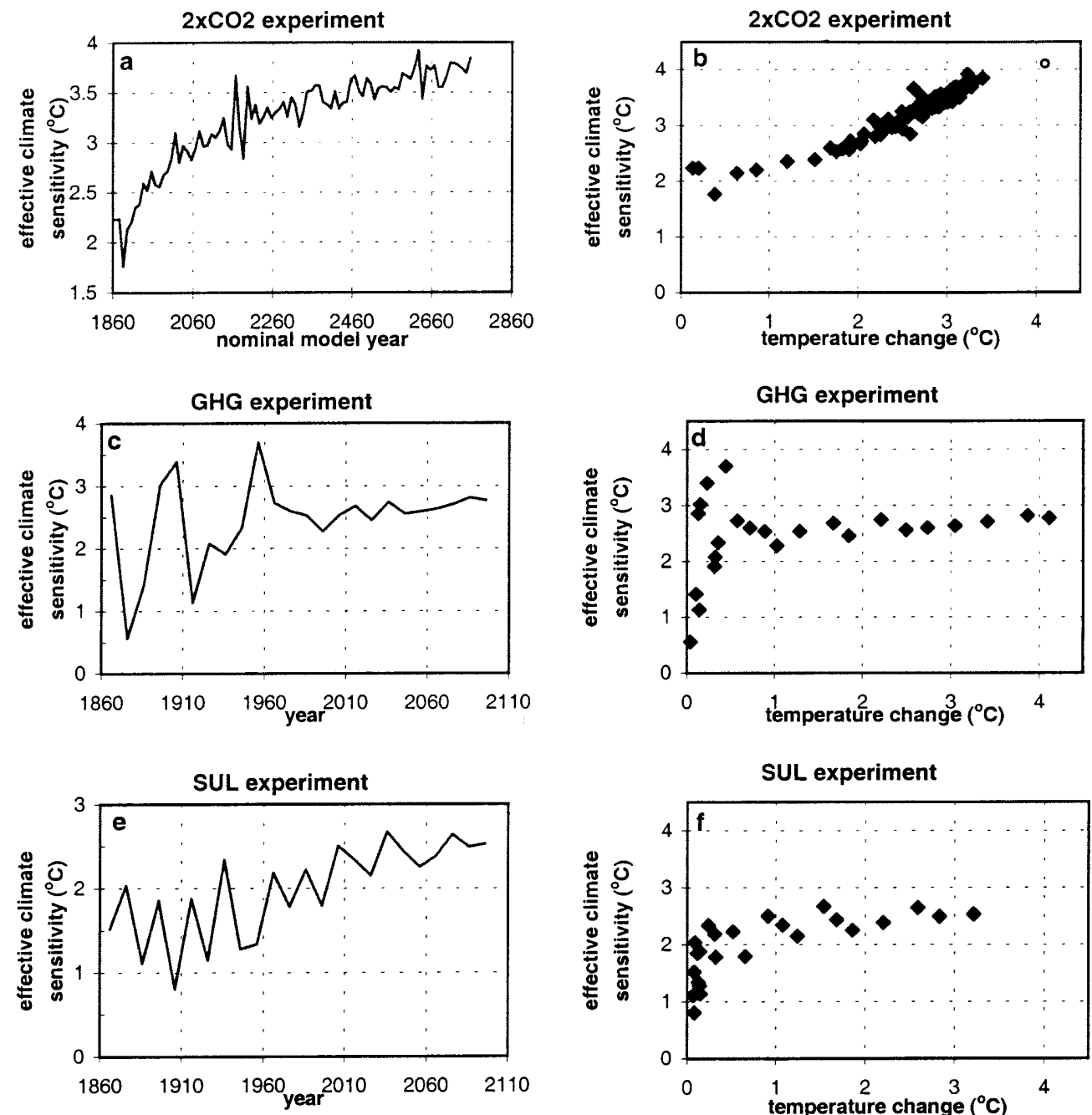

SUL experiment

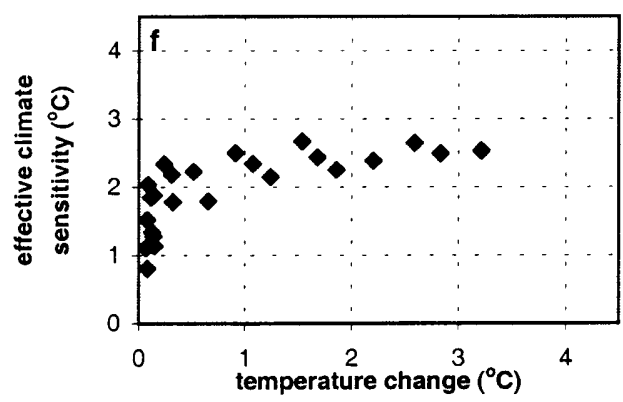

Scenario D
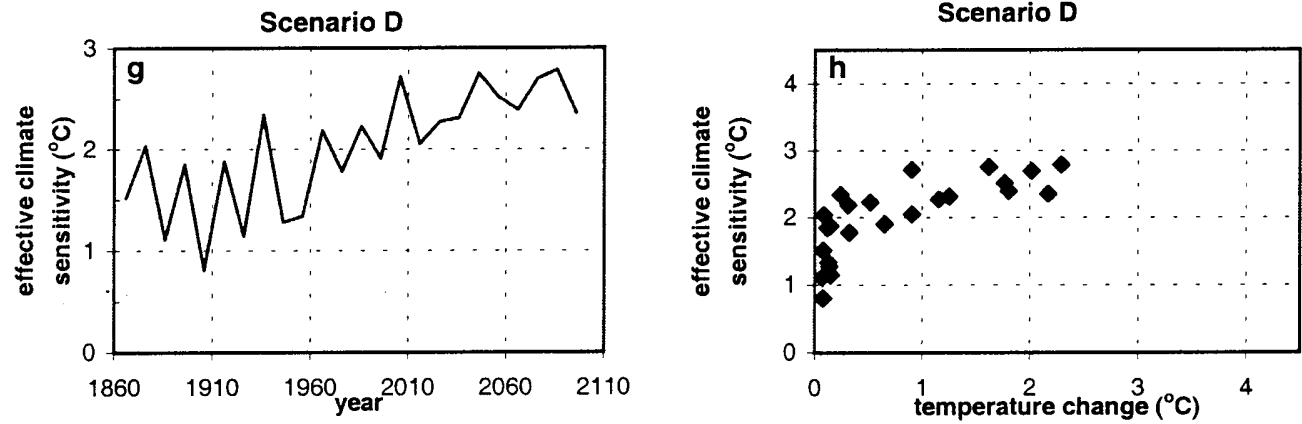

tuned' case (model 2) the variable upwelling rate (Fig. 9) was derived according to Eq. (2) from the changes in the strength of the HadCM2 North Atlantic overturning stream function; it is clear that its time development is not a simple linear function of mixed-layer temperature as assumed in Sect. 2. (Note that there are also lowfrequency changes in this quantity in the HadCM2 control run, as shown by Fig. 16a of Tett et al. 1997.) The results agree well for only the first 150 years or so of the simulations. Eventually, all three UD/EBM versions give a lower surface warming than HadCM2 for the same radiative forcing, on account of their lower, con- stant, climate sensitivity of $2.6{ }^{\circ} \mathrm{C}$. Simulations were also made using the time-dependent effective climate sensitivity values diagnosed from HadCM2. Then 'UD tuned' and the $K=2 \mathrm{~cm}^{2} \mathrm{~s}^{-1}$ simulations (models 2 and 3) overestimate the temperature change and underestimate the expansion compared with HadCM2 because the heat flux into the ocean is too small. The $\Pi=0.85$ simulation (model 4 ) gives a good representation of both temperature change and expansion but does not reproduce well the vertical profile of warming in the ocean. None of the three models captures the midocean warming characteristic of the HadCM2 results. 


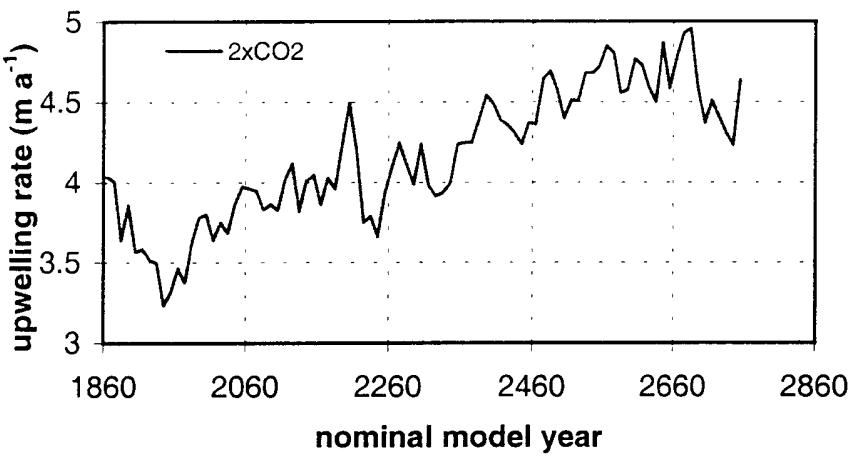

Fig. 9 Derived upwelling rate for the HadCM2 $2 \times \mathrm{CO}_{2}$ experiment, based on the maximum value of the North Atlantic stream function, presented as differences from the corresponding year in the control run

To investigate this further, effective vertical diffusivities are calculated to analyse the heat penetration into the ocean in the HadCM2 experiment in the context of an upwelling diffusion model that uses the same variation with depth of ocean area as the HadCM2 OGCM. In UD/EBMs, the effective diffusivities are larger than the depth-varying vertical diffusivity employed in the A/OGCM, which ranges from $0.1 \mathrm{~cm}^{2} \mathrm{~s}^{-1}$ at the surface to $1 \mathrm{~cm}^{2} \mathrm{~s}^{-1}$ at the bottom (Johns et al. 1997), because they must represent the combined effect of all heat transport processes, other than the upward component of advection (the effects of which are represented by the upwelling terms). Murphy (1995) calculated the time-mean effective diffusivities for the UKTR experiment by fitting the response to a purediffusion model. Here, following Schlesinger and Jiang (1990), the time evolution of the effective diffusivities is calculated. The model and method used for the calculation are described in the Appendix.

Time-dependent effective diffusivities are calculated from decade mean temperature profiles of the long $2 \times \mathrm{CO}_{2} \mathrm{HadCM} 2$ experiment in the framework of the new UD model. The input temperature profiles were taken as the perturbed minus the control temperatures plus the initial control profile. The results with different values for $\Pi$ are similar for depths above about $3000 \mathrm{~m}$ and are, therefore, only shown for $\Pi=0.2$. Both variable upwelling (as in Fig. 9) and constant upwelling are considered, and the results are shown in Fig. 10a, b, respectively.

The effective diffusivities for the variable upwelling case increase substantially with time, especially in the region of maximum values around $2000 \mathrm{~m}$ (starting at less than $2 \mathrm{~cm}^{2} \mathrm{~s}^{-1}$ and rising to values at times in excess of $3 \mathrm{~cm}^{2} \mathrm{~s}^{-1}$ ). In the constant $w$ case, the effective diffusivities at about $2000 \mathrm{~m}$ increase over the first 150 years or so from values of less than $2 \mathrm{~cm}^{2} \mathrm{~s}^{-1}$ to about $2.5 \mathrm{~cm}^{2} \mathrm{~s}^{-1}$; thereafter the values are fairly constant. The increase in the effective diffusivities with variable $w$ in the second half of the experiment is related to the increase in $w$ (see Fig. 9). Thus in the UD model described here, increasing diffusivities are needed to compensate for the cooling effect of increasing $w$, because in Had$\mathrm{CM} 2$ the mid-ocean continues to warm rapidly even while $w$ is increasing. The physics of HadCM2 are not changing as the integration proceeds, but its areaaveraged behaviour is evolving in a way not reflected in the UD physics.

\section{Models with time-constant depth-dependent diffusivity}

Previous sections have shown that the choice of diffusivity is complicated by the interaction of diffusion and upwelling in the UD model. Diffusion alone, for which the equilibrium temperature profile is uniform in depth, cannot account for the initial profile. Possibly, however, diffusion alone might be sufficient to reproduce temperature perturbations. Assuming pure diffusion we find that the $K$ profile diagnosed from the temperature changes averaged over the first 100 years gives good results throughout the simulation when time-varying climate sensitivity is prescribed (model 5 in Table 1).

Given the mismatch between the vertical diffusivities required to obtain a realistic initial temperature profile and those required to transfer the warming signal into the ocean interior, we also try extending the UD model to use two sets of diffusivity profiles. The first profile, which is used to achieve the reference temperature profile, comprises the depth-dependent diffusivities diagnosed to fit the initial HadCM2 temperatures as a steady state. $K$ increases with depth from a surface value of about $0.4 \mathrm{~cm}^{2} \mathrm{~s}^{-1}$ to a maximum at about $2000 \mathrm{~m}$ of $1.9 \mathrm{~cm}^{2} \mathrm{~s}^{-1}$ (see the initial state in Fig. 10a, b). These values can be compared to the uniform $K$ profile of $1 \mathrm{~cm}^{2} \mathrm{~s}^{-1}$ used in Sect. 2 and to the HadCM2 values of $K$, which increase monotonically with depth. The second profile comprises the gradients of the linear least-squares fits to scatter plots of the decadal vertical heat flux values versus vertical temperature gradients for each layer, having first removed the UD-model advective heat flux. Because the linear fits are not constrained to pass through the origin, their gradients are the diffusivities that generate the perturbation heat fluxes from the perturbation temperature gradients. With time-constant $w$, the new model, with two depth-dependent but time-constant diffusivity profiles (model 6 in Table 1), emulates HadCM2 $2 \times \mathrm{CO}_{2}$ results well (Fig. 7).

The $K$ profiles (not shown) applied to the temperature perturbations for the pure-diffusion and ' $2 K$ ' UD/EBMs have maximum $K$ values an order of magnitude larger than typically assumed in the other models. It is these large values that allow the models to transfer more heat into the mid and deep ocean. While showing an improvement over the models using uniform diffusivity profiles or the depth-dependent diffusivity diagnosed to reproduce the initial temperature profile (Fig. 11a), the pure-diffusion model produces too little warming in the upper part of the ocean compensated by too much warming at depth (Fig. 11b). The deep-ocean warming 
Fig. 10a, b Decade mean effective diffusivities $\left(\mathrm{cm}^{2} \mathrm{~s}^{-1}\right)$ derived from the HadCM2 $2 \times \mathrm{CO}_{2}$ experiment within the basis of the UD model shown in Fig. A1. Results are for a variable upwelling rate as in Fig. 7, and $\mathbf{b}$ a constant upwelling rate of $4 \mathrm{~m} \mathrm{y}^{-1}$
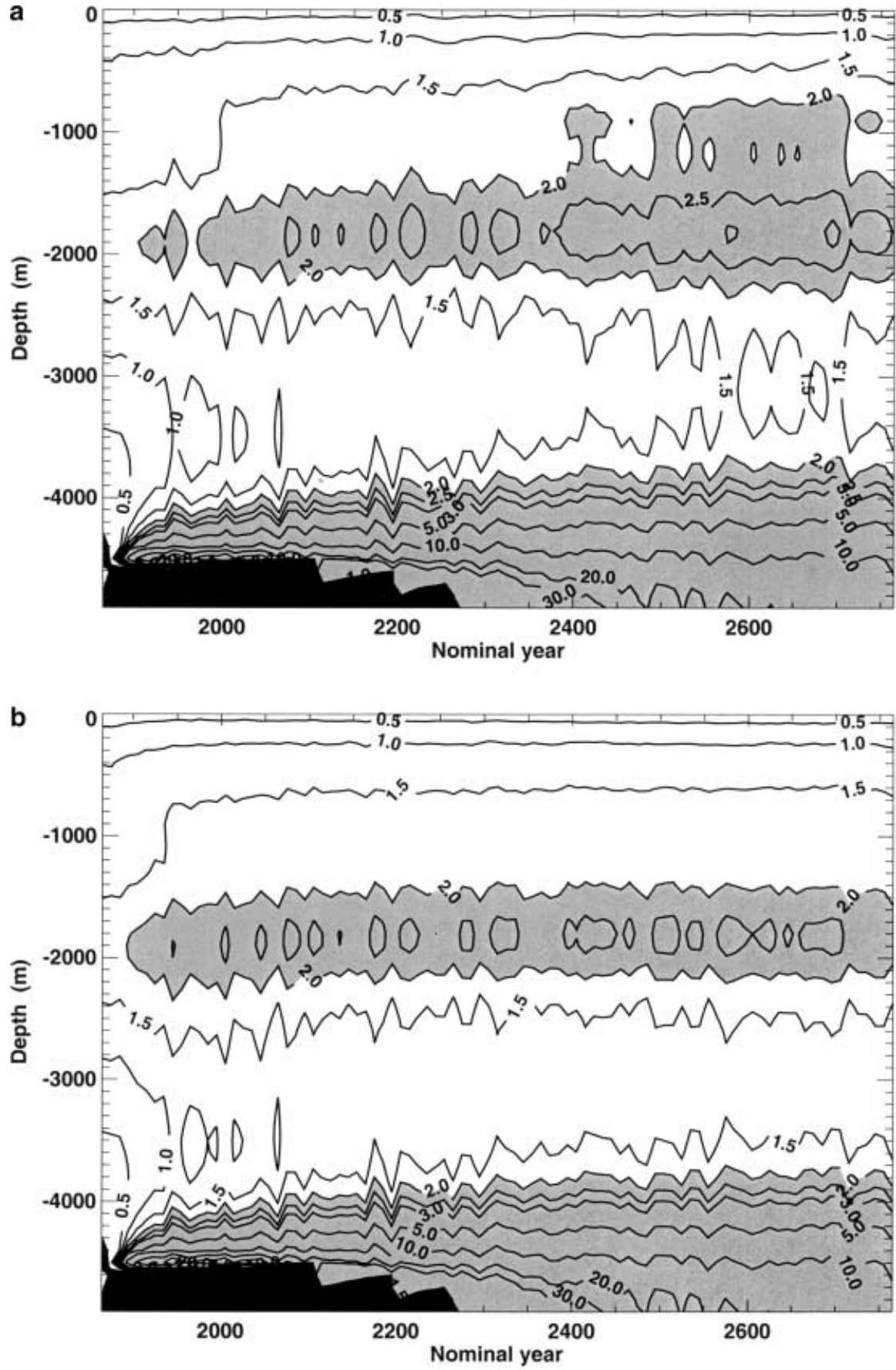

is slightly underestimated in the second half of the run by the ' $2 K$ ' UD/EBM, but overall this model achieves the best fit of the various time-constant $K$ models to the HadCM2 profiles (Fig. 11c).

\section{Surface warming and thermal expansion commitment for $2 \times \mathrm{CO}_{2}$}

The equilibrium $2 \times \mathrm{CO}_{2}$ surface warming and the thermal expansion commitment for the HadCM2 model are not known because the model has not been run to equilibrium. Both the temperature change (Fig. 7a) and the effective climate sensitivity (Fig. 8a) show little sign of approaching equilibrium, even after 900 years, so the 'true' value of the $\mathrm{CO}_{2}$-doubling temperature change commitment for this model is unknown and cannot easily be estimated.

To give a conservative estimate for the thermal expansion commitment, the two UD/EBMs that best emulate the $2 \times \mathrm{CO}_{2}$ results (models 5 and 6 in Table 1) have been integrated to equilibrium using $\Delta T_{2 \mathrm{x}}=$ $3.85^{\circ} \mathrm{C}$, diagnosed from the final decade of the HadCM2 $2 \times \mathrm{CO}_{2}$ experiment. The thermal expansion 


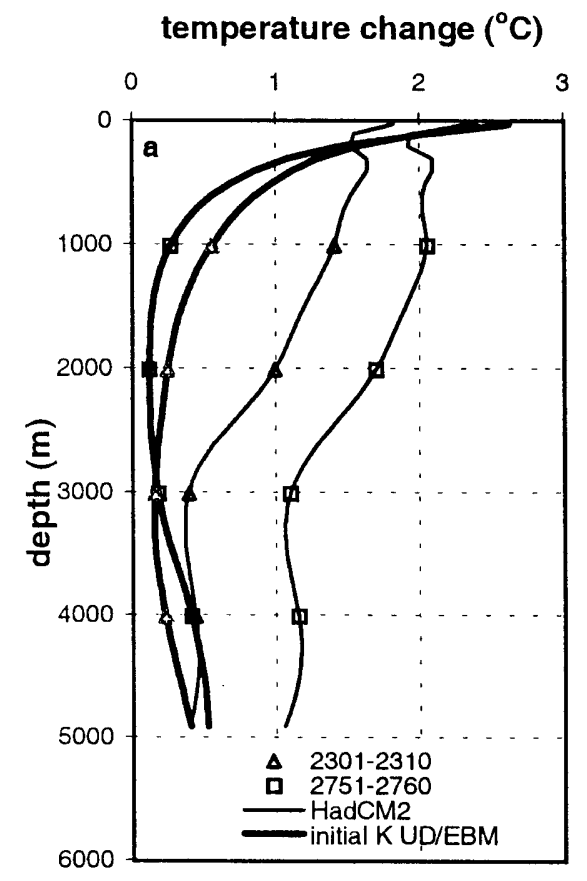

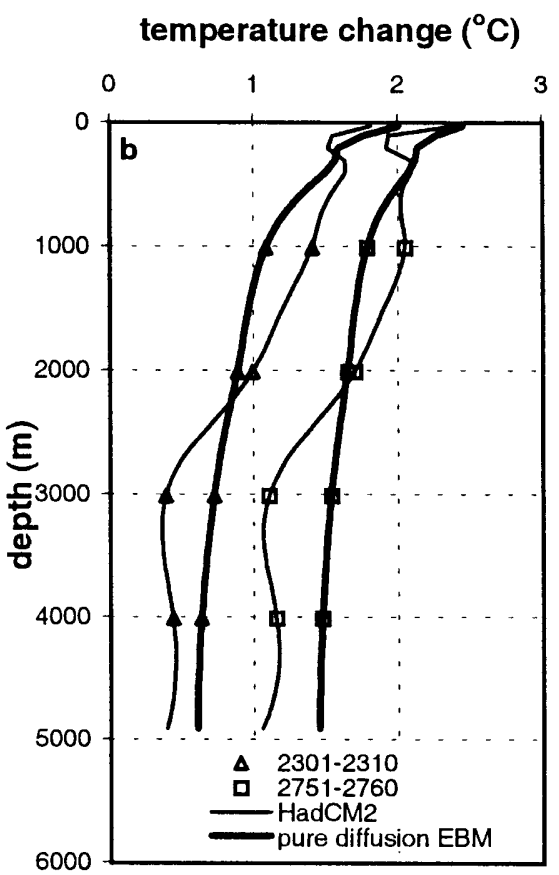

temperature change $\left({ }^{\circ} \mathrm{C}\right)$

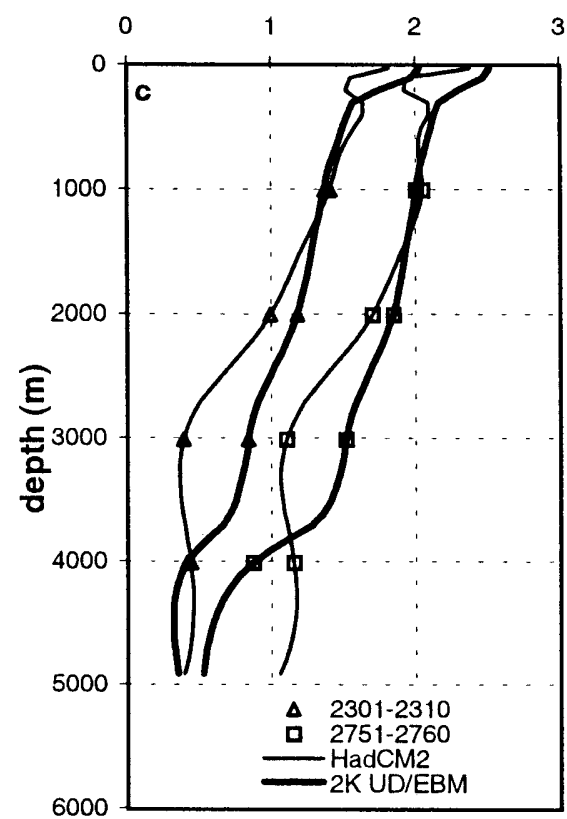

Fig. 11a-c Mid- and end-decade $2 \times \mathrm{CO}_{2}$ experiment temperature change profiles, for three depth-dependant $K$ models. a uses the diffusivitites diagnosed to reproduce the initial temperature profile,

commitments (Table 3) can be compared between the models, and also compared with the commitments obtained if the climate sensitivity that worked well out to 2100 is used $\left(2.6^{\circ} \mathrm{C}\right)$. Results are shown only for a constant upwelling rate of $4.0 \mathrm{~m} \mathrm{a}^{-1}$. The decrease in the expansion commitment between 'UD SAR' and 'UD tuned' from $58 \mathrm{~cm}$ to $46 \mathrm{~cm}$ is largely due to the introduction of the sea-ice parameter. An increase in the diffusivity or a larger value of $\Pi$ leads to larger expansion commitments as shown by models 3 and 4 . The largest expansion commitment is obtained with the pure diffusion model; when $\Delta T_{2 \mathrm{x}}=3.85^{\circ} \mathrm{C}$ the commitment is $170 \mathrm{~cm}$. This is the commitment result for a uniform temperature increase with depth. A similar result is obtained for $\mathrm{UD} / \mathrm{EBMs}$ when $\Pi=1.0$. Even larger expansion commitments are possible according to the $\mathrm{UD} / \mathrm{EBM}$ formulation: the deep ocean could warm more than the surface if $\Pi>1.0$ (conceivable with greater surface warming at high latitudes relative to the ocean mean) or if the thermohaline circulation dramatically slowed or collapsed.

The results in Table 3 should be considered as conservative estimates, given that Fig. 8a suggests a continued increase in effective climate sensitivity above $3.85{ }^{\circ} \mathrm{C}$. The problem then is to predict the effective climate sensitivity as a function of climate state. The relationship between the effective climate sensitivity and the surface temperature change $(\Delta T)$ appears to be quasi-linear (Fig. 8b), so one possibility is to extrapolate this relationship until it intersects with the equilibrium line $\left(\Delta T_{2 \mathrm{x}}=\Delta T\right)$. This gives a value of $6.5^{\circ} \mathrm{C}$ that, when applied to the ' $2 K$ ' UD/EBM model, yields a b uses the perturbation diffusivities for pure diffusion (model 5 in Table 1) and c uses the effective diffusivities in a) together with perturbation diffusivities (model 6 in Table 1)

Table 3 Showing thermal expansion commitment for $2 \times \mathrm{CO}_{2}$ forcing, estimated from various simple models

\begin{tabular}{llll}
\hline UD model type & $\begin{array}{l}\text { Upwelling } \\
\text { rate }\left(\mathrm{ma}^{-1}\right)\end{array}$ & $\begin{array}{l}\Delta T_{2 \mathrm{x}} \\
\left({ }^{\circ} \mathrm{C}\right)\end{array}$ & $\begin{array}{l}\text { Expansion } \\
\text { commitment } \\
(\mathrm{cm})\end{array}$ \\
\hline $\begin{array}{l}\text { Uniform area and diffusivity } \\
\text { 1 UD SAR }\end{array}$ & 4.0 & 2.6 & 58 \\
$\quad$ (Raper et al. 1996) & & & \\
2 UD tuned & 4.0 & 2.6 & 46 \\
3 UD $K=2$ & 4.0 & 2.6 & 60 \\
4 UD $\Pi=0.85$ & 4.0 & 2.6 & 106 \\
Depth dependent area and diffusivity & & \\
5a Pure diffusion & 0.0 & 2.6 & 112 \\
5b Pure diffusion & 0.0 & 3.85 & 170 \\
6a '2 $K$ ' UD/EBM & 4.0 & 2.6 & 88 \\
6b '2 $K$ ' UD/EBM & 4.0 & 3.85 & 133 \\
\hline
\end{tabular}

thermal expansion commitment of $2.35 \mathrm{~m}$. The value of $\Delta T_{2 \mathrm{x}}=6.5^{\circ} \mathrm{C}$ cannot be independently substantiated, however, and we note that the other three simulations yield different relationships.

Senior and Mitchell (2000) argue that the HadCM2 sensitivity in the $2 \times \mathrm{CO}_{2}$ experiment is approaching the 'mixed layer ocean' sensitivity of $4.1^{\circ} \mathrm{C}$. They suggest that the suppression of the sensitivity during the early centuries of the integration was driven by a weakened Southern Hemisphere cloud feedback due to enhanced vertical stability resulting from suppressed warming over the Southern Ocean. The relationship between climate 
sensitivity and temperature change would have to deviate from the quasi-linear behaviour exhibited in Fig. 10b to pass through the point $\Delta T_{2 \mathrm{x}}=\Delta T=4.1{ }^{\circ} \mathrm{C}$ marked on Fig. 10b; such a deviation is entirely possible given that the model would still take many centuries to reach even a $4.1{ }^{\circ} \mathrm{C}$ equilibrium.

Within the context of the UD/EBM, an indicator of suppressed Southern Ocean warming is given by the inter-hemispheric warming contrast. Effective climate sensitivity does not appear to be a simple function of this contrast, however, because it increases throughout the GHG, SUL and D simulations, yet $\Delta T_{2 \mathrm{x}}$ does not decrease during those runs (Fig. 8c, e, g).

In conclusion, a large range in thermal expansion commitment can be simulated by simple climate models. To evaluate the $2 \times \mathrm{CO}_{2}$ expansion commitment directly from HadCM2 would require running the model for several thousand years, which is not practical. On the grounds that it has the best agreement of any with HadCM2 results for the thermal expansion and temperature profiles, we consider that the ' $2 K$ ' UD/EBM model gives the best estimate. Our analysis shows that the commitment would probably be about one to two metres $\left(\Delta T_{2 \mathrm{x}}=3.85,4.1\right.$ and $6.5^{\circ} \mathrm{C}$ give respectively an expansion commitment of $1.3,1.4$ and $2.4 \mathrm{~m}$ ).

\section{Summary and conclusions}

The Raper et al. (1996) version of the Wigley and Raper (1987) upwelling-diffusion model has been modified by the inclusion of a sea-ice parameter. With an appropriate value for this parameter, surface temperature change estimates for anthropogenic forcing are slightly increased and thermal expansion estimates are reduced.

The UD/EBM with three alternative parameter settings can fit the anthropogenically forced surface temperature change and thermal expansion results of the HadCM2 coupled ocean-atmosphere GCM for integrations over the period 1860 to 2100 . In all three cases the climate sensitivity is assumed to be $2.6^{\circ} \mathrm{C}$. The three alternative settings increase the heat flux into the ocean by different means (by decreasing the thermohaline circulation, by increasing the diffusivity or by increasing the warming of the deep water entering at the bottom of the ocean column). None of these, however, capture the mid-ocean warming evident by 2100 in the HadCM2 temperature change profiles.

The HadCM2 $2 \times \mathrm{CO}_{2}$ stabilisation run gives an important opportunity for comparison with UD/EBM results out to a longer time horizon. Unlike the UD/ EBM results with $\Delta T_{2 \mathrm{x}}=2.6{ }^{\circ} \mathrm{C}$, the HadCM2 results show little sign of stabilising even after 900 years. Since in this experiment the HadCM2 surface temperature warming rises above $2.6{ }^{\circ} \mathrm{C}$ and the heat flux into the ocean is greater than that in the UD/EBM, the climate sensitivity must also be larger. Calculation of the HadCM2 effective climate sensitivity reveals that it rises through time (and hence with climate state), first steeply and then more slowly, from a value of about $2{ }^{\circ} \mathrm{C}$ at the beginning of the integration to about $3.9^{\circ} \mathrm{C}$ after 900 years. There appears to be a quasi-linear relationship between the effective climate sensitivity and surface temperature change.

When the time-evolving effective climate sensitivity is used as input to the UD/EBM, the HadCM2 $2 \times \mathrm{CO}_{2}$ surface temperature change and thermal expansion results are well reproduced by using $\Pi=0.85$ (enhanced bottom water warming). The temperature change profiles are poorly replicated, however. Using the other two parameter settings leads to overestimates of the surface temperature change and underestimates of the thermal expansion.

In an attempt to improve the agreement with HadCM2 a UD model is developed with depth-dependent area and diffusivity, both being chosen to match HadCM2. Versions with constant upwelling give the best results. The surface temperature change and thermal expansion can be reproduced with zero upwelling (pure diffusion), but the profile of temperature change is still not well reproduced. The best result in this respect is obtained using a version that has separate diffusivity for the background and perturbation temperature profiles. This, therefore, would seem to be the most satisfactory UD/EBM for purposes including stabilisation scenarios.

The global warming commitment for a doubling in $\mathrm{CO}_{2}$ concentration in HadCM2 is unknown because the climate sensitivity increases throughout the experiment and equilibrium has still not been reached after 900 years. It is evidently higher than the decade 90 effective climate sensitivity of $3.85^{\circ} \mathrm{C}$. After 900 years the HadCM2 expansion continues practically unabated. The $\mathrm{UD} / \mathrm{EBM}$ thermal expansion results indicate that the expansion commitment for HadCM2 $2 \times \mathrm{CO}_{2}$ may be about $1.5-2 \mathrm{~m}$.

\section{Appendix}

\section{Model description}

A schematic representation of an extended UD model is given in Fig. A1. The major structural differences of this model compared

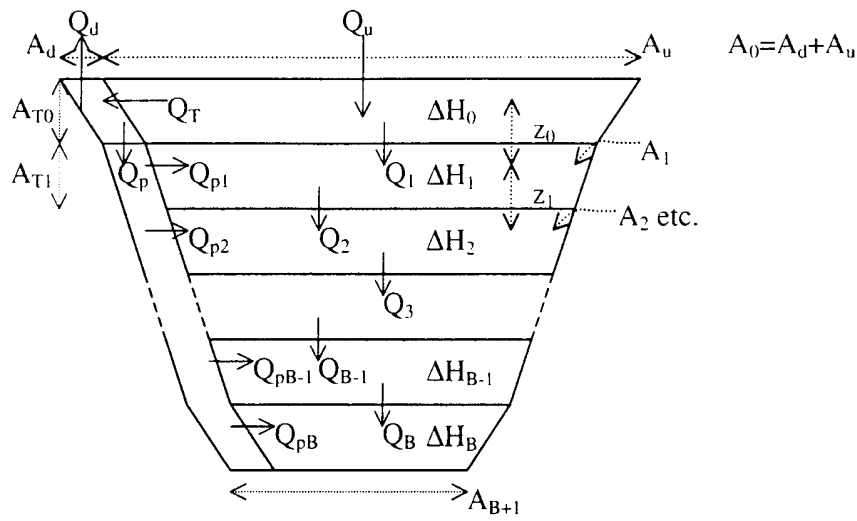

Fig. A1 Symbolic representation of the depth-dependent UD model 
with the model used in Sect. 2 (based on Wigley and Raper 1987) are that the ocean area and the vertical diffusivities are allowed to be depth-dependent. Thus when the areas and $K$ s are constant with depth the extended UD model reverts to the original UD model of Sect. 2. The cross-sectional area of the main water column is taken to decrease with depth as specified in HadCM2, and is denoted $A_{i}$ at the top of layer $i$, with the layers numbered downwards, 0 being the top (mixed) layer. The area of the atmosphere-ocean interface for the main column is $A_{u}$ and of the whole ocean $A_{0}$. The upwelling velocity $w$ in the main column is assumed constant with depth and always upward (positive). The diffusivities $K$ are assumed to depend on depth and the diffusivity at the floor is zero. The polar sinking water column has constant area $A_{d}$ with depth, and sinking water detrains into the main water column, thus maintaining the constant $w$ despite the increasing area as the water moves up the main column. Vertical heat transfer in the sinking column, other than by advection, is not explicitly modelled but it is implied since the temperature is not constant with depth. The area of the sinking column is assumed small compared with that of the main column, so the temperature of the layer 0 of the main column is taken as the mixed layer temperature of the ocean as a whole. There are 50 layers in total and the layers below the mixed layer are $100 \mathrm{~m}$ thick.

The net heat flux into the ocean, $Q_{N}$, is given by

$A_{0} Q_{N}=A_{u} Q_{u}-A_{d} Q_{d}$

and the heat balance for the top polar water layer is

$A_{d} Q_{d}=A_{T 0} Q_{T}-A_{d} Q_{p}$

where $Q_{T}$ and $Q_{p}$ are as shown in Fig. A1, and $A_{T i}$ is the area of the vertical interface of layer $i$ between the main and polar columns. If $\Delta H_{i}$ is the rate of change of the heat content per unit area of layer $i$ in the upwelling column, the heat budget of the mixed layer (the top layer of the main column) is

$\left(\left(A_{0}+A_{1}\right) / 2\right) \Delta H_{0}=A_{u} Q_{u}-A_{T 0} Q_{T}-A_{1} Q_{1}$

where $Q_{1}$ is the downward heat flux at the top of layer 1 of the main column, and $\left(A_{0}+A_{1}\right) / 2$ the area of layer 0 . Substituting for $A_{u} Q_{u}$ from (A1) and then for $A_{d} Q_{d}$ from (A2) gives

$A_{1} Q_{1}=A_{0} Q_{N}-A_{d} Q_{p}-\left(\left(A_{0}+A_{1}\right) / 2\right) \Delta H_{0}$

In this expression, the areas are prescribed, while $Q_{1}, Q_{N}$ and $\Delta H_{0}$ can be evaluated from the A/OGCM. The advective flux $A_{d} Q_{p}$ in the sinking column is unknown. In the UD model, the heat flux $Q_{1}$ in the main column is given by the advection and diffusion terms:

$Q_{1}=w T_{1}+K_{1 / 2}\left(T_{0}-T_{1}\right) /\left(0.5 z_{1}\right)$

where $T_{1}$ is the temperature of layer 1 and $z_{1}$ its vertical thickness. The temperature gradient $\left(T_{0}-T_{1}\right) / 0.5 z_{1}$ applies between the base of layer 0 and the centre of layer 1 , since the mixed layer is assumed to have a constant temperature $T_{0}$ throughout (there is thus a discontinuity in gradient at the base of the mixed layer). In this expression, $T_{1}$ can be evaluated from HadCM2 and $w$ is prescribed by the UD formulation in use. Only $K_{1 / 2}$ is unknown.

The heat budget of the layer $i$ is

$\left(\left(A_{i}+A_{i+1}\right) / 2\right) \Delta H_{i}=A_{i} Q_{i}-A_{i+1} Q_{i+1}+A_{T i} Q_{p i}$

where the heat flux

$Q_{i}=w T_{i}+K_{i-1 / 2}\left(T_{i-1}-T_{i}\right) /\left(0.5\left(z_{i-1}+z_{i}\right)\right)$

As for layer 0 , all the terms are prescribed or can be obtained from HadCM2 except $A_{T i} Q_{p i}$ and $K_{i-1 / 2}$.

The advective heat fluxes in the sinking column can be related by conservation of the heat content of that column. This requires that

$A_{d} Q_{p}=\Sigma A_{T i} Q_{p i}$

where $i$ has values 1 to $\mathrm{B}$ (the bottom layer: 49 are used here). This equation can be used to eliminate $A_{d} Q_{p}$ in Eq. (A3). The areas and the assumption of constant $w$ in the main column dictate the volume fluxes that detrain at each level of the sinking column, and the volume fluxes give the heat fluxes $A_{T i} Q_{p i}$ directly if we know the temperature of the entrained water at each level. We close the problem by assuming the entrained water has the same temperature as the water in the main column at the depth at which it is entrained. However, we cannot make this assumption for the bottom layer B, because Eqs. (A6) and (A7) give

$\left(\left(A_{B}+A_{B+1}\right) / 2\right) \Delta H_{B}=A_{B} Q_{B}+A_{T B} Q_{p B}$

and

$Q_{B}=w T_{B}+K_{B-1 / 2}\left(T_{B-1}-T_{B}\right) /\left(0.5\left(z_{B-1}+z_{B}\right)\right)$

there being no heat flux $Q_{B+1}$ at the ocean floor. But if the temperature of the entrained water at this layer is $T_{B}$, continuity requires that $A_{T B} Q_{p B}=A_{B} w T_{B}$, which will mean $\Delta H_{B}$ cannot be zero while there is a temperature gradient. Physically the problem is that if the bottom layer is colder than the layer above, heat diffuses downward, and this must be balanced by the entry of colder water from the sinking column. Hence we assume that the water entering at the bottom has a temperature $\theta_{B}<T_{B} . \theta_{B}$ is first estimated and then refined as described later, and it warms at some rate relative to the mixed layer temperature (See parameter $\Pi$ in Sect. 2). In this system of equations, $\theta_{B}$ and the diffusivities $\left(K_{i}\right)$ are the only free parameters.

Calculation of diffusivity profile to emulate the initial temperature profile

The values of the $K$ profile and $\theta_{B}$ are first calculated for the initial or reference temperature profile, taken from the first decade mean profile of the HadCM2 control run and assumed to be in equilibrium. Thus the temperature change terms are assumed to be zero as is also $Q_{N}$, the net heat flux into the ocean (in fact the HadCM2 control run has not quite attained a steady state). The corresponding values of $K$ as a function of depth are calculated assuming the incoming bottom water temperature is a little less than the bottom water temperature so as to balance the downward diffusive flux near the bottom. When an ocean-only version of the model is run to equilibrium with the calculated $K$ profile specified, a value of $\theta_{B}=0.80{ }^{\circ} \mathrm{C}$ is diagnosed as being necessary to maintain this initial profile when the bottom water temperature is not specified.

When time-dependent temperature changes, and hence heat fluxes, are prescribed using HadCM2 results, the time dependent diffusivities can be diagnosed (see main text).

Acknowledgements The work at the Climatic Research Unit was supported by the Commission of the European Communities Framework IV project 'Climate Change and Sea Level' (ENV4CT095-0124), and the work at the Hadley Centre for Climate Prediction and Research was supported by the UK Department of the Environment, Transport and the Regions under contract PECD 7/12/37 and by the Public Meteorological Service Research and Development Programme.

\section{References}

Bretherton FP, Bryan K, Woods JD (1990) Time-dependant greenhouse-gas-induced climate change. In: Houghton JT, Jenkins GJ, Ephraums JJ (eds) Climate change. The IPCC scientific assessment. Cambridge University Press, pp 175-193

Church JA, Godfrey JS, Jackett DR, McDougall TJ (1991) A model of sea-level rise caused by ocean thermal expansion. J Clim 4: 438-456

Cubasch U, Hasselmann K, Höck H, Maier Reimer E, Mikolajewicz U, Santer BD, Sausen R (1992) Time-dependent greenhouse warming computations with a coupled oceanatmosphere model. Clim Dyn 8: 55-69

Cubasch U, Santer BD, Hellbach A, Hegerl G, Höck H, MaierReimer E, Mikolajewicz U, Stössel A, Voss R (1994) Monte 
Carlo climate change forecasts with a global coupled oceanatmosphere model. Clim Dyn 10: 1-19

Gregory JM (1993) Sea level changes under increasing atmospheric $\mathrm{CO}_{2}$ in a transient coupled ocean-atmosphere GCM experiment. J Clim 6: 2247-2262

Gregory JM, Mitchell JFB (1997) The climate response to $\mathrm{CO}_{2}$ of the Hadley Centre coupled AOGCM with and without flux adjustment. Geophys Res Letts 24: 1943-1946

Gornitz V, Lebedeff S, Hansen J (1982) Global sea level trends in the past century. Science 215: 1611-1614

Harvey LDD (1994) Transient temperature and sea level response of a two-dimensional ocean-climate model to greenhouse gas increases. J Geophys Res 99: 18 447-18 466

Harvey LD, Schneider SH (1985) Transient climate response to external forcing on $10^{0}-10^{4}$ year time scales Part 1: experiments with globally averaged, coupled, atmospheric and ocean energy balance models. J Geophys Res 90: 2191-2205

Hoffert MI, Flannery BP (1985) Model projections of the timedependent response to increasing carbon dioxide. In: MacCracken MC, Luther FM (eds) Projecting the climatic effects of increasing carbon dioxide. US Department of Energy, Carbon Dioxide Research Division, pp 149-190

Hoffert MI, Callegari AJ, Hsieh CT (1980) The role of deep sea heat storage in the secular response to climate forcing. J Geophys Res 85: 6667-6679

Johns TC, Carnell RE, Crossley JF, Gregory JM, Mitchell JFB, Senior CA, Tett SFB, Wood RA (1997) The second Hadley Centre coupled ocean atmosphere GCM; model description, spinup and validation. Clim Dyn 13: 103-134

Kattenberg A, Giorgi F, Grassl H, Meehl GA, Mitchell JFB, Stouffer RJ, Tokioka T, Weaver AJ, Wigley TML (1996) Climate models - projections of future climate. In: Houghton JT, Meira Filho LG, Callander BA, Harris N, Kattenberg A, Maskell K (eds) Climate change 1995. The science of climate change. Contribution of Working Group 1 to the Second Assessment Report of the Intergovernmental Panel on Climate Change, Cambridge University Press, Cambridge, pp 363-443

Levitus S (1982) Climatological atlas of the world oceans. NOAA Prof Pap 13, US Government Printing Office, Washington DC, USA

Manabe S, Stouffer RJ (1994) Multiple century response of a coupled ocean-atmosphere model to an increase of atmospheric carbon dioxide. J Clim 7: 5-23
Mitchell JFB, Johns TC (1997) On the modification of global warming by sulfate aerosols. J Clim 10: 245-267

Mitchell JFB, Johns TC, Gregory JM, Tett SFB (1995) Climate response to increasing levels of greenhouse gases and sulfate aerosols. Nature 376: 501-504

Murphy JM (1995) Transient response of the Hadley Centre coupled ocean-atmosphere model to increasing carbon dioxide. Part III: analysis of global-mean response using simple models. J Clim 8: 496-514

Raper SCB, Cubasch U (1996) Emulation of the results from a coupled general circulation model using a simple climate model. Geophys Res Lett 23: 1107-1110

Raper SCB, Wigley TML, Warrick RA (1996) Global sea-level rise: past and future. In: Milliman JD, Haq BU (eds) Sea-level rise and coastal subsidence: causes, consequences and strategies. Kluwer Academic, Dodrecht, pp 11-45

Schimel D, Grubb M, Joos F, Kaufmann R, Moss R, Ogana W, Richels R, Wigley T (1997) Stabilization of atmospheric greenhouse gases: physical, biological and socio-economic implications. In: Houghton JT, Meira Filho LG, Griggs DJ, Maskell K (eds) IPCC Technical Paper III

Schlesinger ME, Jiang X (1990) Simple model representation of atmosphere-ocean GCMs and estimation of the time scale of $\mathrm{CO}_{2}$-induced climate change. J Clim 3: 1297-1315

Senior CA, Mitchell JFB (2000) The time dependence of climate sensitivity. Geophys Res Lett (in press)

Tett SFB, Johns TC, Mitchell JFB (1997) Global and regional variability in a coupled AOGCM. Clim Dyn 13: 303-323

Warrick RA, Le Provost C, Meier MF, Oerlemans J, Woodworth PL (1996) Changes in sea level. In: Houghton JT, Meira Filho LG, Callander BA, Harris N, Kattenberg A, Maskell K (eds) Climate change 1995. The science of climate change. Contribution of Working Group 1 to the Second Assessment Report of the Intergovernmental Panel on Climate Change, Cambridge University Press, Cambridge, pp 359-405

Wigley TML, Raper SCB (1987) Thermal expansion of sea water associated with global warming. Nature 330: 127-131

Wigley TML, Raper SCB (1992) Implications for climate and sea level of revised IPCC emissions scenarios. Nature 357: 293-300

Wigley TML, Raper SCB (1993) Future changes in global mean temperature and thermal expansion-related sea level rise. In: Warrick RA, Barrow EM, Wigley TML (eds) Cambridge University Press, Cambridge, pp 111-133 